\title{
An Experimental Study on Productivity Improvement using Workstudy and Ergonomics
}

\author{
Malashree P', Vinayak N Kulkarni2*, V. N. Gaitonde ${ }^{3}$, Sahebagowda M $^{4}$ \\ ${ }^{I}$ Mechanical Department, B.V.B. College of Engineering and Technology, Hubballi, Karnataka, INDIA \\ ${ }^{2 *}, 3$ Shool of Mechanical Engineering, KLE Technological University, Hubballi, Karnataka, INDIA \\ ${ }^{4}$ Mechanical Department, Veerappa Nisty Engineering College, Shorapur, Karnataka, INDIA
}

\begin{abstract}
The work is carried out to determine the cycle time to produce rolling shutter and propose a better method to reduce the cycle time of the same using work study techniques and also recommend the ways to reduce fatigue level of worker using Ergonomics approach at metal section industry. As the manufacturing process does not have efficient work procedure and workers are exaggerated by unwanted fatigue, so the industry is not able to improve productivity. Thus, the purpose of this work is to suggest improvement areas to improve its productivity and efficiency by analyzing the problems associated with it. Identified problems were solved by video work study technique. An improvement in industry was achieved by minimizing the cycle time, changing the sequence of operation and reducing the workers fatigue. Work pro software is used for analyzing the data and to develop the proposed method.
\end{abstract}

Keywords: Method study, Time study, Standard time, Video work study and Ergonomics.

\section{Introduction}

Work study is the systematic examination of the methods of carrying out activities to improve the effective use of available resources such as man, material, money and machinery to set up standards of performance for the activities being carried out. It is one of the strongest tools that a management can use to improve productivity [1].

The proposed work is done in a metal section industry which engaged in producing rolling shutter. The company provides variety of rolling shutters, according to the customer requirement. An important problem faced in production system of this industry is the time taken to produce a roller shutter. There is a scope for productivity improvement.

This paper explores the use of video work study technique and also explains about how the study has been made with regards to existing method for different work stations to determine the cycle time and suggests a proposed method to reduce production cycle time of the same and to improve productivity.

Motion study is carried out for Ergonomics study by capturing video of welding process using a video recorder. Motion Film is analyzed for each motion element of workers body posture. The results obtained by the motion study, reveal various fatigue causing and time consuming factors related to workers.

\subsection{Problems Identified}

- The design of the workplace layout is poor.

- Workers are affected by unwanted fatigue.

- Efficient work procedures have not been adopted.

\subsection{Objectives of Study}

- To study the present work process and identify bottle neck areas.

- To suggest a new improved method to reduce the cycle time of the same.

- To minimize the production time of rolling shutter and also to minimize excess man power.

- To improve the relationship between the worker and machine by using proper ergonomical consideration 


\section{Literature review}

A general term for method study and work measurement which are used in the analysis of human work in all its circumstances, and which leads to the exploration of all factors which influence the efficiency and economy of the situation being reviewed, in order to effect improvement [1]. The effect of Work study has been addressed by a number of researchers: Darshan et al. [3] used video work study technique to reduce the cycle time and to suggest a new improved method at assembly work station of valve industry by using the work pro software. Murshida Khatun came up with comparison between the productivity and efficiency before and after applying work study techniques[4]. Their main aim was to improve production method, reduce production time, effort minimization and improvement of Ergonomics. Satish [5] presented a case study in the development of time study and applying in the engine block manufacturing plant. Their work highlighted in combining two operations in one single machine by adjustments of fixtures. Kamble and Kulkarni [6] carried out a study on improving the productivity by reducing the cycle time. They studied the existing method and cycle time of assembly work station of valve industry and proposing new method for it. Shinde and Jadhav [7] by using method study, Ergonomic study was carried out. By observing each element of motion film they came up with modified work station layout to reduce workers fatigue. Tapiwa et al. [8] optimized the research into Fertilizer Company. The data which is collected throughout the year have identified problems in performance quality and breakdowns. It can be seen that there were futile in maintenance system. These causes were managed by the researchers. Mishra [9] proposed improvement areas in industry to increase the productivity by reducing cycle time of the product carrying from injection molding machine to direct on trolley instead of pallet to proceed in the paint shop department. Using method study they came up with idea by removing pallet proposed to keep component directly on the trolley instead of pallet this will save time and will reduce the worker's fatigue so that worker can produce more component in a day.

\section{Data collection by manual work study method}

Operation process chart is put up for all the sections to identify the number of operations and inspections which are present. Manual work study is carried out at the assembly section of shutter.

Following are the shutter assembly sections where the flow process charts are done:
1. Curtain Section
2. Drum Assembly Section
3. Side Channel
4. Bottom Channel

5. Bracket

6. Hood Cover

7. Inspection

8. Painting and Packing Section

A flow process chart is prepared for existing method in which we use symbols such as operation, inspection, transportation, delay, storage, and combined activity as shown in Table 1.

Table 1: Sample of Existing flow process chart drawn for producing rolling shutter.

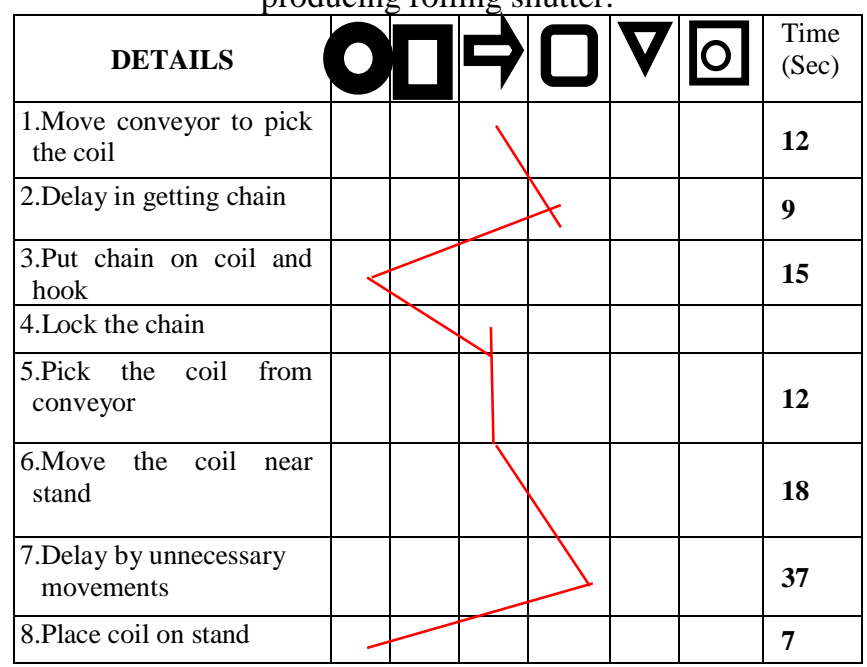

As in existing method there is unnecessary movement by the worker, the worker each time goes to the store room to get the tools, rivets, fasteners like nuts, bolts, washers etc... which results in delay. Hence, we designed a tray for Curtain Assembly Section and Drum Assembly Section separately which can reduce the unnecessary movements by which delay can be minimized and can reduce the workers. Combining the activities, as shown in below table 2 .

Table 2: Sample of Proposed flow process chart drawn for producing rolling shutter.

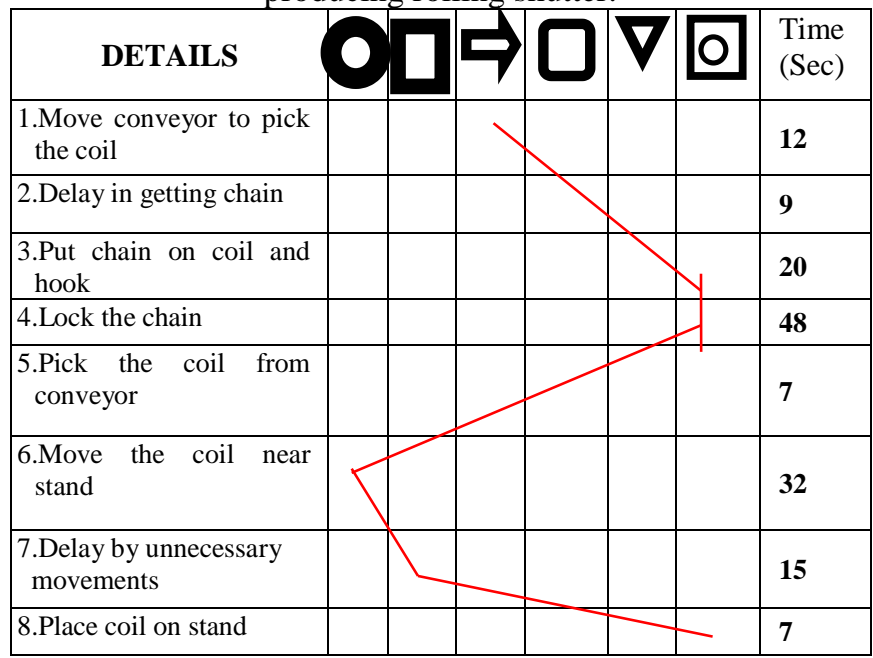


After generating present and proposed method flow charts we can summarize the chart as shown below in table 3 .

\subsection{Summary chart}

Table 3. Summary of present and proposed method of manual work study

\begin{tabular}{|l|c|c|c|}
\hline \multicolumn{1}{|c|}{ Activity } & $\begin{array}{c}\text { Present } \\
(\mathrm{sec})\end{array}$ & $\begin{array}{c}\text { Proposed } \\
(\mathrm{sec})\end{array}$ & $\begin{array}{c}\text { Saving } \\
(\mathrm{sec})\end{array}$ \\
\hline Operations & 5582.5 & 4211 & 1371.5 \\
\hline Inspection & 67 & 47 & 20 \\
\hline Transportation & 617 & 179 & 438 \\
\hline Delay & 545 & 473 & 72 \\
\hline Storage & 0 & 0 & 0 \\
\hline $\begin{array}{l}\text { Combined } \\
\text { Activity }\end{array}$ & 0 & 1130 & -1130 \\
\hline Total & 6811.5 & 6040 & 771.5 \\
\hline
\end{tabular}

According to the manual work study the present method takes 114 mins to produce one model of rolling shutter and the proposed method takes 102 mins to produce one model of rolling shutter. Hence Savings is 12 mins.

- $\%$ of improvement $=(($ Present method - Proposed method)/Present method $* 100$

$\bullet$

$$
\begin{aligned}
& =((6811-6040) / 6811) * 100 \\
& =11.32 \%
\end{aligned}
$$

3.2 Discussions on the manual work study results: The table 1 shows, the summary of the Manual Work Study of existing and proposed method. In Existing method there is lot of time spent in unnecessary movements by worker and delay because of poor work place layout. In new method, by changing work layout most of the non-value added activities have been eliminated. It will improve the existing process by reducing number of work stations, unnecessary transportations and combining the operations by this we can reduce workers fatigue.

3.3 Video work study: The video work study consists of recording all the pattern of motions involved in performing the whole work cycle. As in this project there is lot of hand motions and movements of the worker in assembly section. Hence Video Work Study is done at shutter assembly section. Steps followed in video work study for recording are:

- List the proper equipage for the purpose of recording the video.

- Choose the proper equipage for the purpose of recording of the video.

- Locate the camera such a way that it covers entire work place layout.

- Edify the worker that this study is for advancement of the process and say him not to be afraid or annoyed and to work normally as he works daily.
- Locate the flood light at proper place if there is no sufficient amount of light.

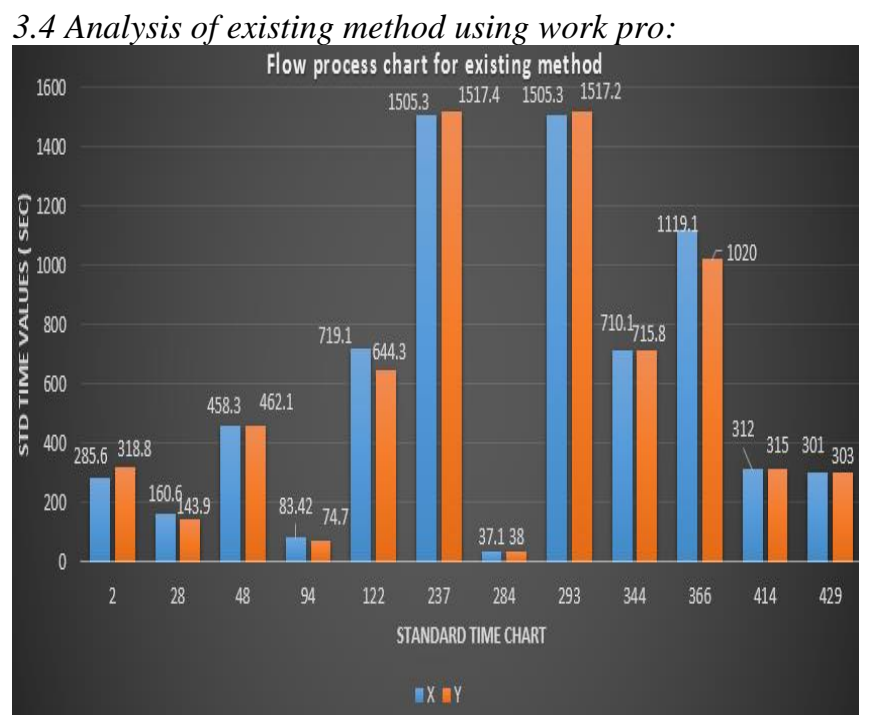

Figure 1. Standard time chart for existing method

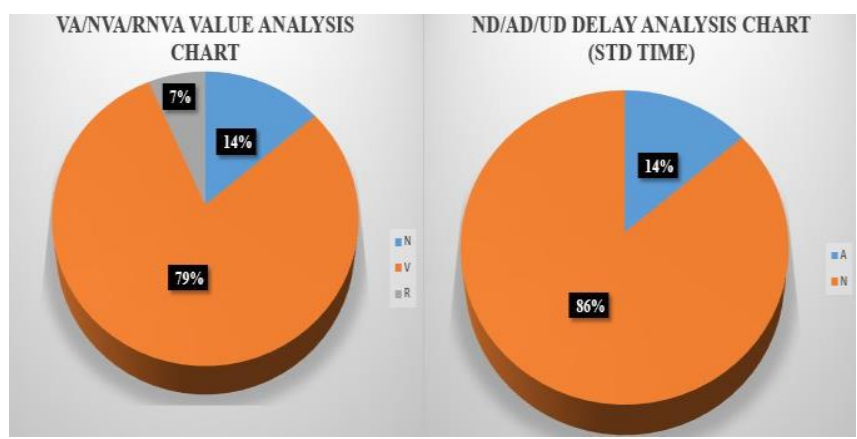

Figure 2. Lean analysis chart for existing method

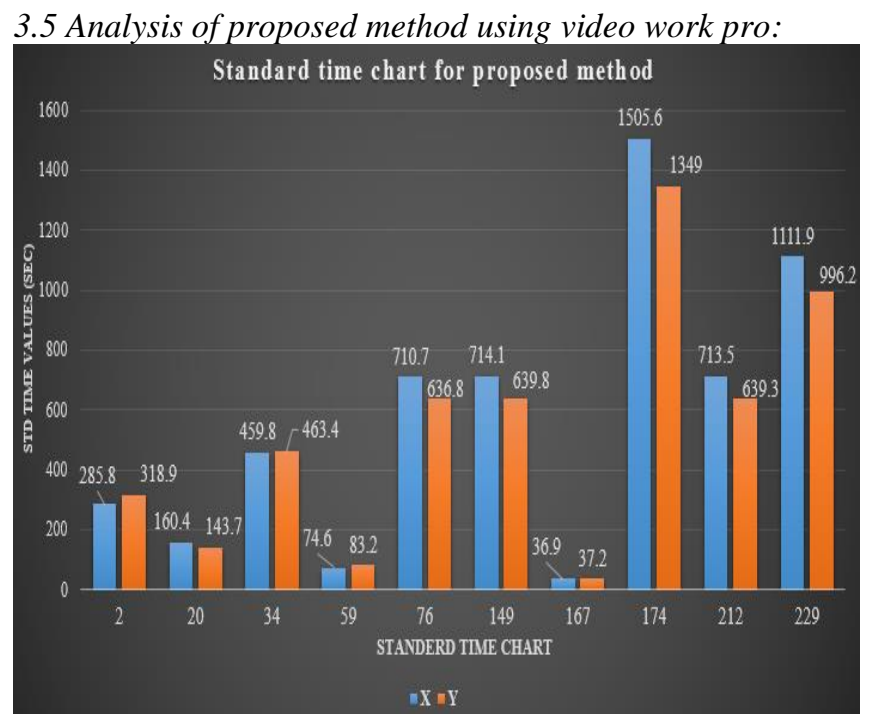

Figure 3. Standard time chart for proposed method 


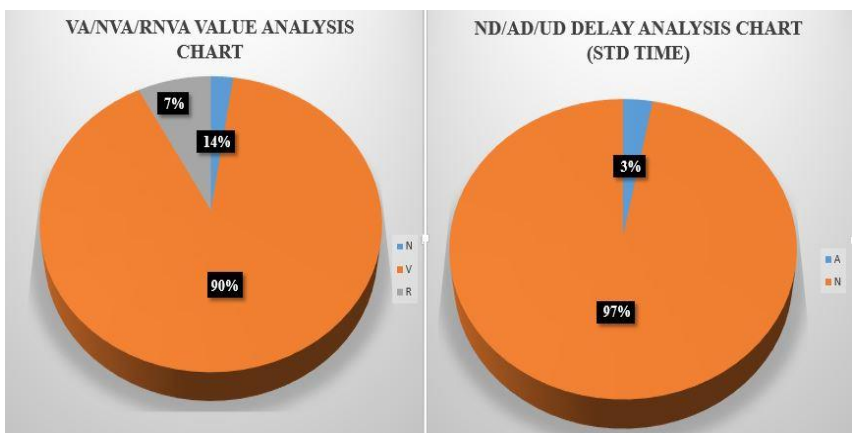

Figure 4. Lean analysis chart for proposed method

3.6 Discussions on the analysis of video work study: After the analysis is done by using work-pro software, the following are the facts examined during the analysis

- In Existing Method, fig. 1 shows the standard time chart. Based on the Histogram, we can know that the standard time required for completing various activities is $6596.95 \mathrm{secs}$.

- In existing method, figure 2 shows the Lean analysis chart. It shows that value adding activity involved in assembly section is $79.50 \%$, required value adding activity involved is $6.63 \%$ and non-value adding activity involved is $13.87 \%$ which shows nonavoidable delay is $86.13 \%$ and avoidable delay is $13.87 \%$.

- In proposed method, figure 3 shows the standard time chart, Based on the Histogram, we can know that the standard time required for completing various activities is $6116.85 \mathrm{secs}$.

- In proposed method, figure 4 shows the Lean analysis chart. It shows that value adding activity involved in assembly section is $90.05 \%$, required value adding activity involved is $7.66 \%$ and nonvalue adding activity involved is $2.29 \%$.

3.7 Productivity improvement: So productivity improvement per day at assembly section of rolling shutter from table 2 is $=$ 8 shutters/day

- Existing productivity $=6$ shutters per day

- Improved productivity $=8$ shutters /day

- Increase in profit per year $=5760000-4320000=$ 1440000

It will improve the current process by reducing the unnecessary movements of worker and by reducing workers fatigue. After implementing the suggested improvement areas the industry is able to increase its productivity.

3.8 Ergonomics: Ergonomics Study is conducted on assembly work station in a welding shop. The main focus of this study is to identify fatigue causing factors, which leads to reduce efficiency of workers. When asked to the workers about the postures and complex task they informed that they get frequently neck pain, back pain because of bending, wrist pain. Hence Ergonomic study is carried out using application of motion study by video work study. The data is collected by using video recorder and carried out with RULA and REBA assessment.

3.8.1 RULA (Rapid Upper Limb Assessment): In exiting method, the workers are investigated through RULA worksheet; it consists of two areas for assessment of body which splits into Posture A and Posture B. This method investigates the body parts as lower arm, upper arm, wrist twist, wrist, trunk, neck and limb. The working postures of worker and the angle at which they are working are recorded by using video and is being input into work pro software. In figure 5 we can observe that upper and lower arm postures are +3 and +2 is obtained according to the RULA score worksheet. Hence the final score of upper arm is 3 and the lower arm is 2 . In figure 5 , we can observe the neck position of the pose of the operator related to the worksheet is selected and it shows the score as 3 . Now there is inclination of trunk which gives the score as +4 and score of neck is +3 . Considering all these Postures from posture A and Posture B we get final score as 6 . Which indicates that medium risk, further investigation, changes are required soon. Hence it came up with proposed method. In proposed method, from figure 6 we can observe that upper and lower arm postures are +1 and +1 were obtained according to RULA score worksheet. Hence the final score of upper arm is 1 and the lower arm is 1 . From figure, we can observe the neck position of the pose of the operator related to the worksheet is selected and it shows the score as 2 . Now there is inclination of trunk which gives the score as 1 and score of neck is +2 .

Considering all these postures from posture A and Posture $\mathrm{B}$ we get final score as 3 . Which indicates low risk, changes may require.

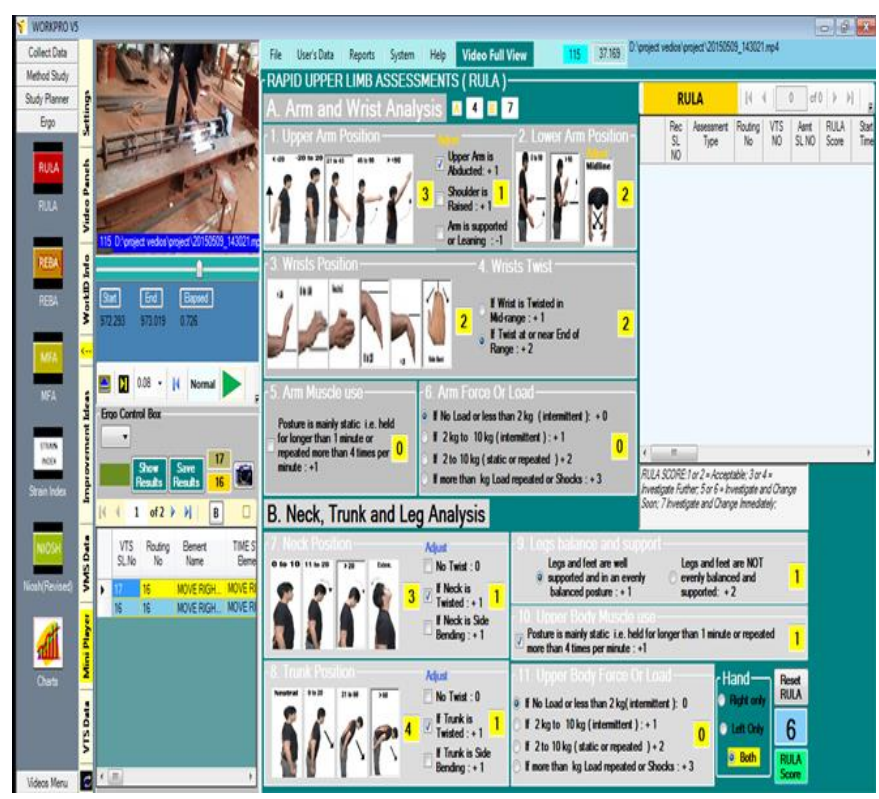

Figure 5. RULA existing method 


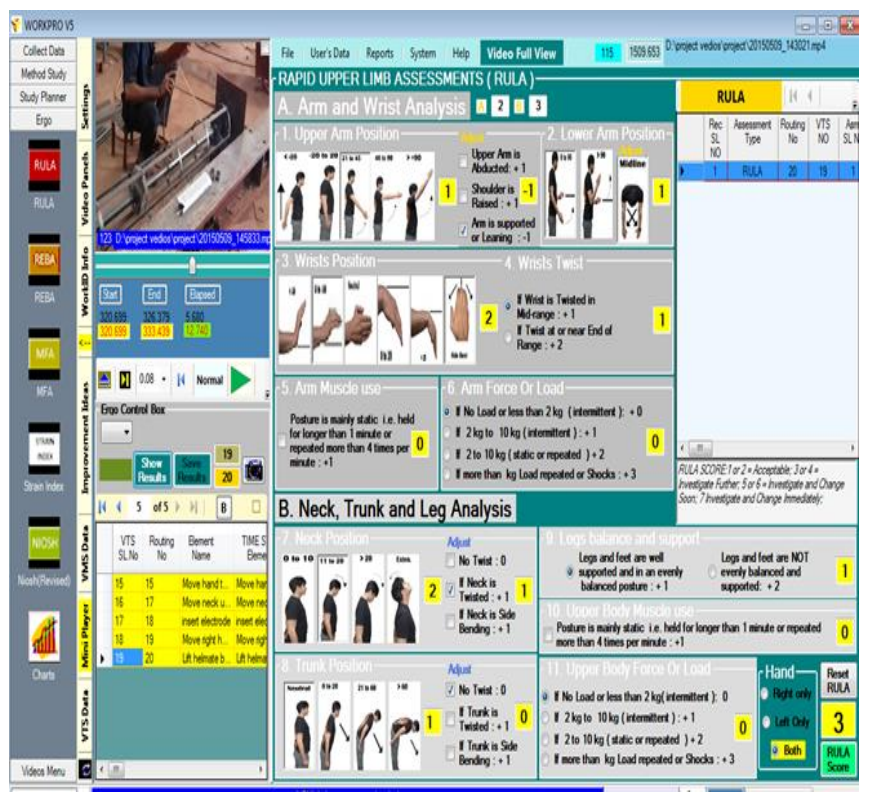

Figure 6. RULA proposed method

As shown in figure 6 here after changing the body posture the RULA score is reduced from 6 to 3 . Hence there is improvement which will reduce the workers fatigue.

3.8.2 REBA (Rapid Entire Body Assessment): In exiting method, the workers are investigated through REBA worksheet; REBA worksheet which is divided into two sections, label A and label B. Label A contains neck trunk and leg analysis whereas Label B contains Arm and wrist analysis. In figure 7 we can observe that neck position of the pose of the operator is given as +2 by using worksheet. As there is inclination in trunk posture its score is given as +4 . The legs are bent hence its score is given as 1 and 2. Where as in Label B, we can observe that the upper and the lower arm postures are +3 and +1 is obtained, according to RULA score worksheet. The score of wrist is given by 2 . Considering all these postures from posture A and Posture B we get final score as 11 , which indicates very high risk. Hence came up with proposed method.

In proposed method, from figure 8 we can observe that neck position of the pose of the worker is given as +2 by using worksheet. As there is inclination in trunk posture its score is given as +1 . The legs are bent hence its score is given as 2 and 2. Where as in Label B, we observed that the upper and the lower arm postures are +2 and +1 is obtained, according to RULA score worksheet. The score of wrist is given by 2. After the data of each region is collected and scored, tables on the form are then used to compile the risk factor variable, generating a single score which represents the level of MSD risk. Considering all these postures from posture A and Posture B we get final score as 7, which indicates medium risk.

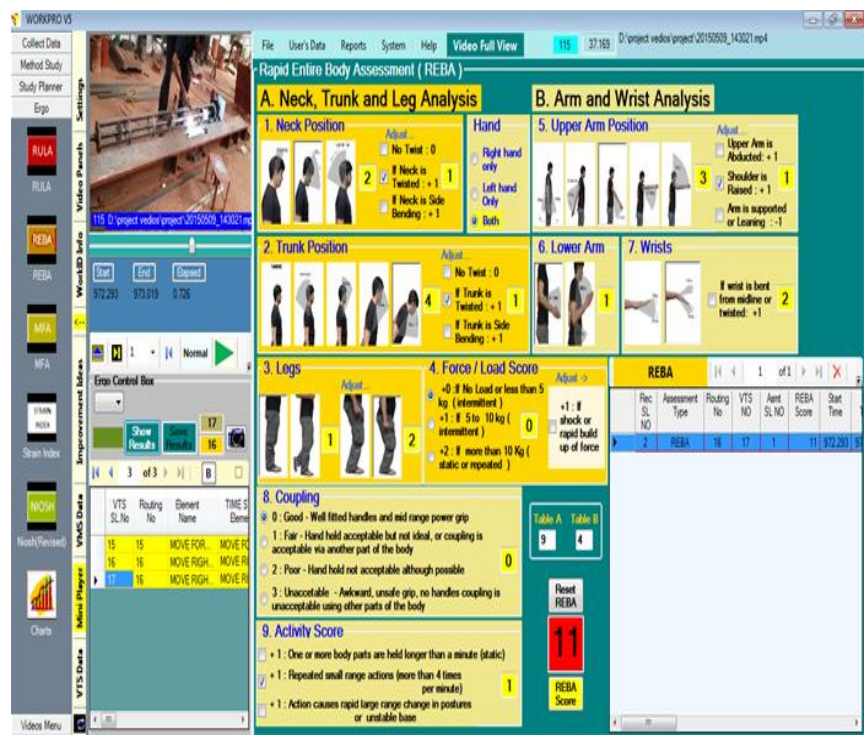

Figure 7. REBA existing method

As shown in figure 7 the REBA score for existing method is 11 and level of MSD is Very high risk, implement changes required as soon as possible.

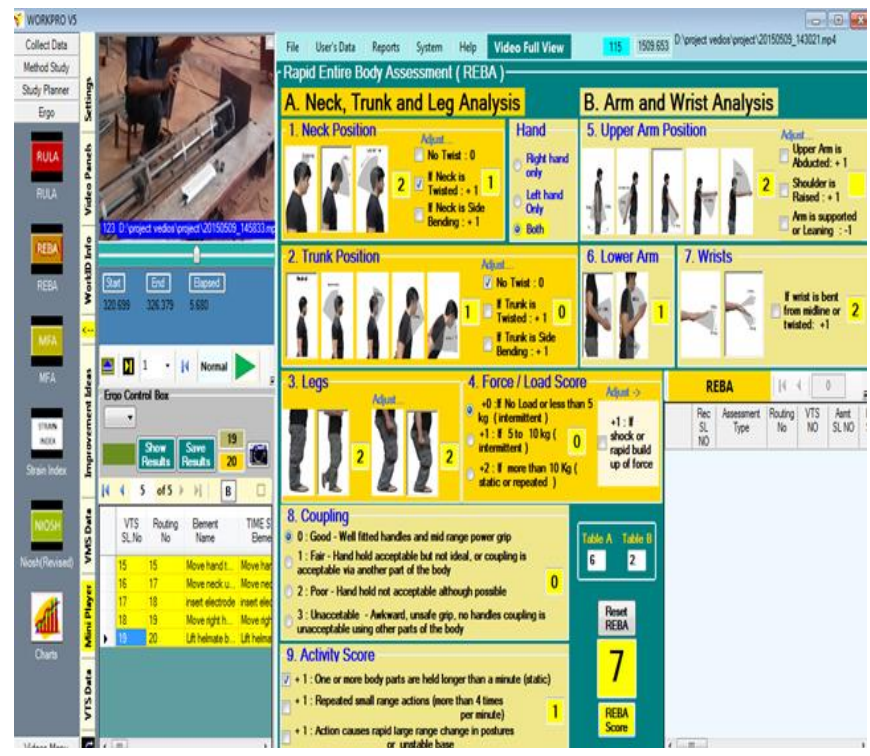

Figure 8. REBA proposed method

As shown in figure 8 here after changing the body posture the REBA score is reduced from 11 to 7 . Hence there is an improvement in REBA score which will reduce worker fatigue.

\section{Conclusions}

From the manual work study summary table, it can be concluded that the process can be improved based on method study, work procedure and with proper utilization of resources. It will improve the existing process 
by reducing number of work stations, unnecessary transportations and combining the operations.

After the analysis is done by using work-pro software, the following are the facts examined during the analysis: the time study is being performed on each operations being carried out while manufacturing rolling shutter and cycle time of component is observed as 110 mins. By implementing the proposed method cycle time is reduced from 110mins to 102 mins. Thus reducing cycle time by 8 mins. This improves productivity by $7.27 \%$.

Implementation of the work study helps in improving the layout, reducing cycle time and reduces workers fatigue.

The assessment of body posture has been carried out using RULA and REBA tools. It can be concluded that the major proportion of workers are working in uncomfortable and painful postures as found by analysis. Thus the workers are under modest to high risk of MSDs as determined from RULA and REBA risk levels.

\section{References}

1. Geneva, International Labor Organization, Introduction to work study, International Labor Office, Fourth edition 1992.

2. Ralph M Barnes, Motion and time study design and measurement of work, seventh edition 1900.

3. Darshan, K.R., Nithin Nayak, Pavan Kulkarni, Prashant Singh, and Vinayak Kulkarni (2012), 'Productivity improvement using work study techniques at assembly work station', International journal of social science and management ISSN: 2319-300X.
4. Murshida Khatun (2013), 'Application of industrial engineering technique for better productivity in garments production', International journal of science, Environment and technology, vol. 2, No 6, 2013, 1361-1369.

5. Satish Keru Raut (2014), 'A case study of productivity improvement by using IE tools', International journal of innovations in engineering research and technology, vol. 1, issue 1, Nov-2014.

6. Ravi Kamble and Vinayak Kulkarni, 'Productivity improvement at assembly section using work study techniques', International journal of research in engineering and technology, eISSN: 2319 -1163 | pISSN: 2321-7308.

7. Gurunath, V., Shinde and Jadhav, 'Ergonomic analysis of an assembly workstation to identify time consuming and fatigue causing factors using application of motion study', International journal of engineering and technology.

8. Mutombozana Tapiwa, Mugwindiri Kumbirayi, and Chikuku Tauyanashe, 'The use of work study techniques in optimizing manufacturing plant maintenance process: an investigation into a fertilizer manufacturing company in Zimbabwe', International journal of science and research, ISSN: 2319-7064.

9. Rishabh Mishra, (2015) 'Productivity improvement in automobile industry by using method study' International Journal of Scientific Engineering and Applied Science, Volume-1, Issue-4, ISSN: 23953470.

10. Sahebagowda, Vinayak Kulkarni, Chetan Kapali, Ergonomics Study for Injection Moulding Section using RULA and REBA Techniques, International Journal of Engineering Trends and Technology, Vol 36, No 6, pp 294-301, 2016.

\section{Biographical notes}

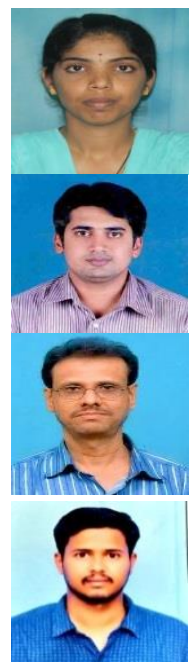

Malashree P obtained degree of Bachelor of Engineering in Industrial and Production Engineering in the year 2013 from B. V. Bhoomaraddi College of Engineering and Technology, Hubli, Karnataka, India and Master of Technology degree in Production Management in the year 2015 from B.V. Bhoomaraddi College of Engineering and Technology, Hubli, Karnataka, India. Her areas of interest include work study and Design of experiments

Vinayak N Kulkarni is working as Asst. Professor in School of Mechanical Engineering at KLE Technological University, Hubballi, INDIA. His areas of interest are production, management, manufacturing and automation. He is pursuing his Ph.D under the guidance of Dr. V.N.Gaitonde in the area of Machining of Shape Memory Alloys.

Dr. V. N. Gaitonde is a Professor in School of Mechanical Engineering at KLE Technological University, Hubballi, India. He has more than 25 years of teaching and research experience. He is the editorial board member of four international journals and reviewer for many international journals. He has more than 90 papers in refereed international journals.

Sahebagowda has completed his M.Tech in production management in the year 2016 from B V Bhoomaraddi college of Engineerring and Technology - Hubballi. Basicaly he is a Mechanical Engineer and is presemntly working in Veerappa Nishti Engineering college, Shoropur. Karnataka. 